\title{
General symptom reporting in female fibromyalgia patients and referents: a population-based case-referent study Karin Björkegren $^{* \dagger 1}$, Mari-Ann Wallander ${ }^{\dagger 1}$, Saga Johansson ${ }^{\dagger 2,3}$ and Kurt Svärdsudd ${ }^{\dagger}$
}

Address: ${ }^{1}$ Department of Public Health and Caring Sciences, Family Medicine and Clinical Epidemiology Section, Uppsala University Hospital, Uppsala, Sweden, ${ }^{2}$ AstraZeneca R\&D Mölndal, Department of Epidemiology, Mölndal, Sweden and ${ }^{3}$ Department of Medicine, Sahlgrenska University Hospital/Östra, Gothenburg, Sweden

Email: Karin Björkegren* - karin.bjorkegren@pubcare.uu.se; Mari-Ann Wallander - mari-ann.wallander@pubcare.uu.se; Saga Johansson - saga.johansson@astrazeneca.com; Kurt Svärdsudd - kurt.svardsudd@pubcare.uu.se

* Corresponding author †Equal contributors

Published: 31 October 2009

BMC Public Health 2009, 9:402 doi:10.1 I86/147|-2458-9-402
Received: 12 February 2009

Accepted: 3I October 2009

This article is available from: http://www.biomedcentral.com/I47I-2458/9/402

(c) 2009 Björkegren et al; licensee BioMed Central Ltd.

This is an Open Access article distributed under the terms of the Creative Commons Attribution License (http://creativecommons.org/licenses/by/2.0), which permits unrestricted use, distribution, and reproduction in any medium, provided the original work is properly cited.

\begin{abstract}
Background: Fibromyalgia is characterized by widespread musculoskeletal pain and palpation tenderness. In addition to these classic symptoms, fibromyalgia patients tend to report a number of other complaints. What these other complaints are and how often they are reported as compared with related referents from the general population is not very well known. We therefore hypothesized that subjects with fibromyalgia report more of a wide range of symptoms as compared with referents of the same sex and age from the general population.
\end{abstract}

Methods: I 38 women with diagnosed fibromyalgia in primary health care and $40 \mathrm{I}$ referents from the general population matched to the cases by sex, age and residential area responded to a postal questionnaire where information on marital status, education, occupational status, income level, immigrant status, smoking habits physical activity, height and weight history and the prevalence of 42 defined symptoms was sought.

Results: The cases had lower educational and income levels, were more often unemployed, on sick leave or on disability pension and were more often first generation immigrants than the referents. They were also heavier, shorter and more often had a history of excessive food intake and excessive weight loss. When these differences were taken into account, cases reported not only significantly more presumed fibromyalgia symptoms but also significantly more of general symptoms than the referents. The distribution of symptoms was similar in subjects with fibromyalgia and referents, indicating a generally higher symptom reporting level among the former.

Conclusion: Subjects with fibromyalgia had a high prevalence of reported general symptoms than referents. Some of these differences may be a consequence of the disorder while others may reflect etiological processes. 


\section{Background}

Fibromyalgia is a syndrome characterized by widespread musculoskeletal pain and increased palpation tenderness. Fibromyalgia prevalence has been estimated to two to four percent in the general population, [1-3] with strong female predominance $[1,4]$. The syndrome is chronic, with little or no healing tendency. There are many hypotheses regarding etiology.

According to the American College of Rheumatology (ACR) 1990 criteria, the fibromyalgia diagnosis is based on tender points in a minimum of 11 of 18 specific sites and widespread pain, i.e., axial pain plus pain above and below the waist and in the right and left side of the body and for at least 3 months $[5,6]$. In addition, numerous other symptoms, such as fatigue, sleep disturbances, morning stiffness, irritable bowel syndrome (IBS) [5,7-9], headache, psychological distress [8,9] and subjectively impaired cognitive function $[8,10]$, are commonly reported. Laboratory findings are usually normal [6]. Moreover, fibromyalgia patients have difficulties in performing activities of daily living [11], affecting their quality of life negatively [12], they have limited work capacity and are often on disability pension [11]. This circumstance and their frequent use of health care resources have negative financial consequences in relation to public health costs $[1,9,11,12]$.

Most of the symptoms mentioned above have been linked to the fibromyalgia condition, although they are not strictly part of the current classification criteria. However, it might be that fibromyalgia patients have more widespread symptoms than generally believed, which might be evidence that fibromyalgia has its origin in the nervous system rather than in the musculoskeletal. We therefore decided to test the hypothesis that women with fibromyalgia, in addition to traditional fibromyalgia symptoms, report more of a wide range of general symptoms than women in the corresponding age segment of the general population in a case-referent study large enough to allow for adjustments for potential confounders or other symptom prevalence affecting variables.

\section{Methods \\ Study population}

The study was performed in Uppsala county, central Sweden. All patients in the county who fulfil the 1990 ACR criteria [5] for fibromyalgia diagnosis are offered referral to a fibromyalgia patient educational team, run by one of the authors (KB), with including medical and physiotherapy competence at a primary health care center in the city of Uppsala. All fibromyalgia patients in the county who fulfill the criteria are entered into a fibromyalgia patient register and are offered a rehabilitation programme. The vast majority of all diagnosed fibromyalgia patients in the county are included in the program.

From this register, the 150 most recently entered female patients were sampled. For each case five referents, matched to the cases by age, sex and residential area (postal code), were sampled from the national population register, which is required by law to be kept up-todate. The population register includes all residents of Sweden, whether citizens or not, and persons are identified by name, address, and a unique personal identification number that includes information on date of birth and sex. The matched case-referent groups were numbered consecutively (referred to as match number below). A questionnaire, presented as a general health survey, was mailed to all the 900 cases and referents, of which 138 (92.0\%) cases and 401 (53.5\%) referents responded after one reminder when necessary. Overall there were responses from cases and at least one matched referent in $90.0 \%$ of case-referent matched groups.

\section{Data collection}

From the postal questionnaire, information was obtained regarding marital status, number of children and number of children still in the household, working status, educational background, household income, immigrant status, smoking habits, physical activity at work and during leisure time, height, weight and weight history, presence of presumed fibromyalgia and other symptoms, and menstrual status.

Marital status was classified as never married, married or cohabiting, divorced or widowed. Occupational status was classified as working full time outside the home, or being a student, working part time, unemployed, on sick leave for more than six months, retired because of disability, old age pensioner, or other status. Highest attained educational level was classified as compulsory (secondary) school only, vocational training, secondary school, or college or university education. Annual household income from work before taxes was given at the one of five possible levels shown in Table 1 (1 SEK approximately equalling 0.14 US $\$$ or $0.10 €$ ). If the respondent was a first generation immigrant, the country of origin was requested, and for second generation immigrants the country of origin for each of the parents.

Smoking habits were classified as never smoked, exsmoker, currently smoking less than 15 grams per day, smoking 15-24 grams per day, or smoking 25 or more grams per day, one cigarette equalling 1 gram, a cigarillo 2 grams and a cigar 5 grams. Wet snuff-taking habits were classified accordingly, one portion equalling 1 gram. Leisure time physical activity was classified into four levels ranging from sedentary lifestyle to vigorous physical activ- 
Table I: Study population

\begin{tabular}{|c|c|c|c|c|c|c|c|}
\hline & \multicolumn{2}{|l|}{ Cases } & \multicolumn{2}{|c|}{ Referents } & \multirow[b]{2}{*}{$\mathbf{p}$} & \multirow[b]{2}{*}{ OR } & \multirow[b]{2}{*}{$95 \% \mathrm{Cl}$} \\
\hline & Mean or \% & SD & Mean or \% & SD & & & \\
\hline$N$ & 138 & & 401 & & & & \\
\hline Age, years & 49.5 & 8.79 & 48.8 & 8.25 & n.s. & 0.97 & $0.93-0.997$ \\
\hline Marital status, \% & & & & & n.s. & & \\
\hline Single & 7.4 & & 9.3 & & & & \\
\hline Married or cohabiting & 71.1 & & 73.4 & & & & \\
\hline Divorced & 18.5 & & 15.0 & & & & \\
\hline Widowed & 3.0 & & 2.3 & & & & \\
\hline No. of children & 2.4 & 1.16 & 2.2 & 1.28 & n.s. & & \\
\hline \multicolumn{8}{|l|}{ Migrant status, $\%$} \\
\hline Ist generation immigrant & 20.3 & & 9.7 & & $<0.001$ & 2.39 & $1.40-4.06$ \\
\hline 2nd generation immigrant & 2.9 & & 4.0 & & n.s. & & \\
\hline Education, \% & & & & & $<0.001$ & 0.80 & $0.65-0.98$ \\
\hline Secondary school only & 22.0 & & 8.8 & & & & \\
\hline Vocational training & 17.7 & & 16.5 & & & & \\
\hline High school & 31.6 & & 23.3 & & & & \\
\hline College or university & 28.7 & & 51.4 & & & & \\
\hline Occupational status, $\%$ & & & & & $<0.001$ & 3.58 & $2.63-4.86$ \\
\hline Working full time & 10.3 & & 52.1 & & & & \\
\hline Working part time & 15.4 & & 26.4 & & & & \\
\hline Unemployed, on sick-leave or retired & 74.3 & & 19.4 & & & & \\
\hline Other & - & & 2.1 & & & & \\
\hline Income level (SEK/year), \% & & & & & $<0.001$ & 0.90 & $0.75-1.08$ \\
\hline$<100.000$ & 16.1 & & 5.2 & & & & \\
\hline $100,000-149,000$ & 19.7 & & 8.3 & & & & \\
\hline $150,000-199,000$ & 12.2 & & 11.6 & & & & \\
\hline $200,000-299,000$ & 19.9 & & 28.7 & & & & \\
\hline$>300.000$ & 32.1 & & 46.2 & & & & \\
\hline Pain duration, years & 16.0 & 11.8 & - & - & & & \\
\hline
\end{tabular}

Characteristics of the study population.

ity [13]. Physical activity at work was classified as sedentary, physically mobile work, or physically heavy work [13].

Information on height was sought to the nearest centimetre and weight to the nearest kilogram. Body mass index (BMI) was calculated as weight in kilograms divided by height in metres squared. In addition, information was sought on recalled weight at age 20, weight five years ago, highest weight ever attained, the respondent's ideal weight, whether the respondent had experienced periods of perceived underweight, or periods of excessive food intake, and the weight at that time. Furthermore, the question "How is your weight distributed?" was asked with response alternatives "on the belly/upper part of the body", "on the hips/thighs" and "equally in both locations" to obtain information on the subjects' body mass distribution.

Two sets of symptom reporting questionnaires were used. General symptoms were measured with the Complaint Score sub-scale of the Gothenburg Quality of Life Instru- ment [14]. The instrument contains a list of 30 general symptoms, listed in figure 1 . The respondent was asked to indicate which of these symptoms she had experienced during the past three months with possible responses "yes" (=1) or "no" (=0). The symptoms form six symptom groups. The scores are summed to an overall Complaint Score, possible range 0-30, and may also optionally be summed across the symptom groups. The instrument is not intended to measure the prevalence of specific diseases but rather the tendency to report symptoms.

Based on presumed fibromyalgia symptoms listed in previous publications $[1,5,11,15]$, a symptom list including the twelve most common and a few atypical symptoms was compiled. The respondent was requested to indicate what symptoms she experienced during the past 3 months. In addition, for those reporting pain the pain history duration, measured in years, was sought. Information on menstrual status was based on a question about whether the menstruation had ceased, and if so, what year the last menstrual period occurred. 


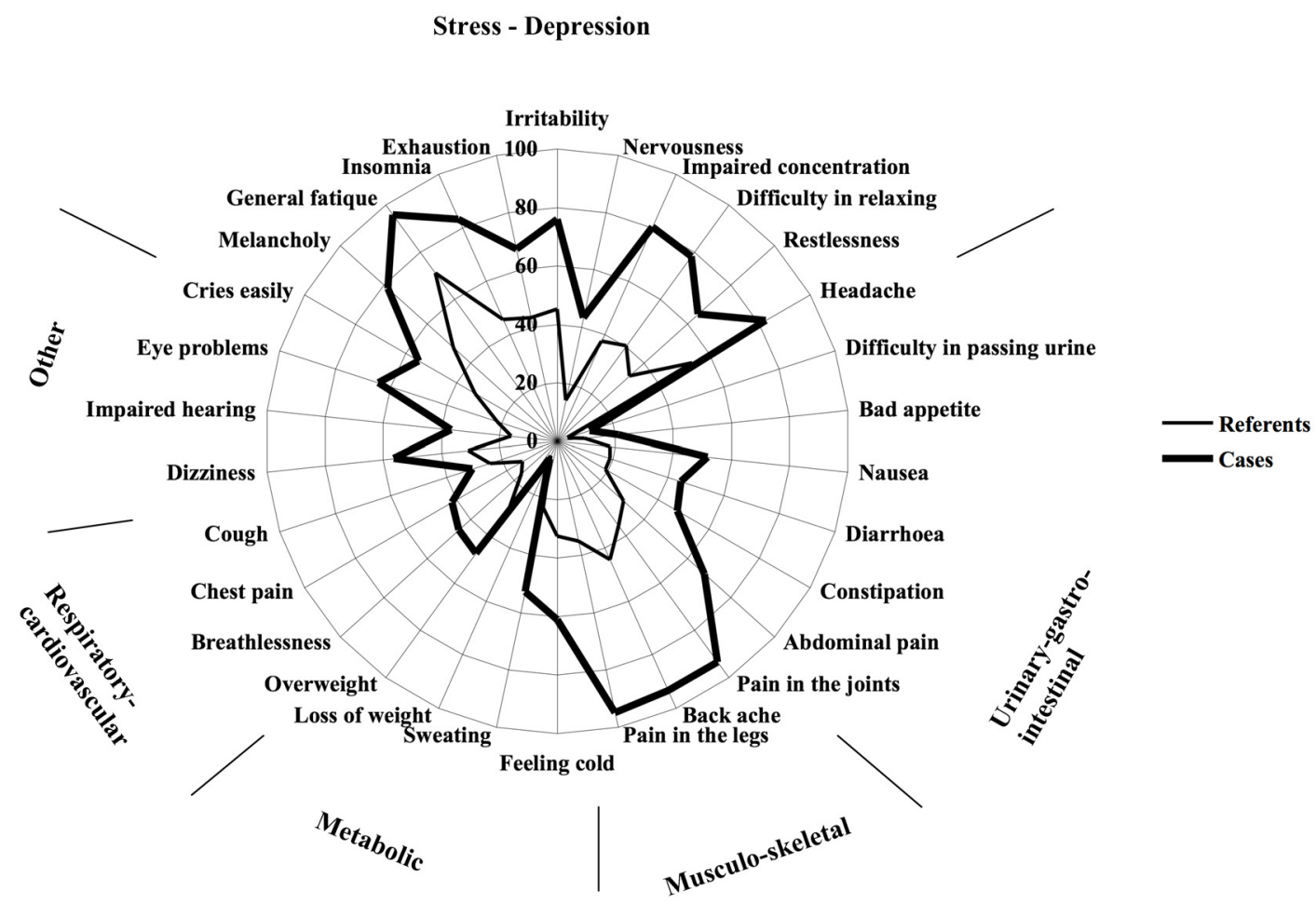

Figure I

General symptom prevalence. Polar diagram showing the prevalence of 30 general symptoms experienced during the past three months among fibromyalgia patients and age-sex-residential area matched referents from the general population. The symptoms are arranged according to symptom groups.

There were no differences between respondents and nonrespondents regarding age or place of residence in the total study population or within the case group and reference group, respectively.

The study was performed in accordance with the Helsinki Declaration. All respondents gave their informed consent to participation in the study. The Research Ethics Committee at the Medical faculty, Uppsala University, approved the study (Ups 01-088).

\section{Statistical analysis}

The analyses were performed with the SAS software [16]. Summary statistics such as means and dispersion measures were computed according to conventional parametric methods. Simple differences between the two groups in continuous variables were tested with Student's t-test and differences in proportions with the chi-square test.

The analyses of differences in symptom reporting were performed with logistic regression analysis, producing odds ratios and their $95 \%$ confidence intervals $(95 \% \mathrm{CI})$, with the symptom entered as dependent variable (out- come) and the group variable (case or referent) as the independent variable. To adjust for the influence on outcome of the significant differences in characteristics between the groups, these (immigrant status, education, occupational status, income, and BMI) were entered as covariates in the analyses, with backward elimination of non-significant covariates. All analyses were conditional, i.e., cases were compared only with their own referents, to avoid bias owing to the variable number of responding referents per case. This was achieved by using the match number as an additional covariate in the analyses. Only two-tailed tests were used. P-values of less than 5\% were regarded as statistically significant.

\section{Results}

\section{Characteristics of the study population}

There were no differences between the groups regarding age, marital status, or number of children, Table 1 . The cases were first generation immigrants significantly more often than the referents, and had, on average, less education. A lower proportion of cases than referents had a job, and cases had lower income than referents. There were no 
differences between the groups in proportion of postmenopausal women or mean age at menopause.

Lifestyle variables, weight, and weight history are shown in Table 2. The cases were similar to the referents in tobacco use, physical activity and body mass index (BMI) at age twenty. Present height, weight, and BMI differed between the groups, with the cases being significantly shorter and heavier than the referents. There was no difference in dominating body mass distribution (waist or hips/thighs) between the groups. Significantly more cases than referents reported underweight or excessive food intake ever.

\section{Symptom reporting}

The prevalence rates of presumed fibromyalgia symptoms during the past three months are displayed in Table 3. As expected, the cases had a significantly higher prevalence of all symptoms, also when the influence on symptom reporting of the covariates immigrant status, education, occupational status, income, and BMI was taken into account $(\mathrm{p}<0.0001)$. The odds ratios ranged from a low
4.10 for muscular fatigue to a high 31.33 for daily dull aching.

The mean number of reported symptoms in the Complaint Score instrument was 17.7 (SD 5.89) among the cases and 8.9 (SD 5.41) among the referents when the influence of the covariates was taken into account ( $\mathrm{p}<$ 0.0001). As shown in Table 4 and Figure 1, the Complaint Score difference was not confined to any special symptom or symptom group. Generally, cases appeared to report symptoms more often than referents, the differences between the groups being significant for 25 of the 30 symptoms.

\section{Discussion}

The cases thus had more symptoms than the referents, not only regarding fibromyalgia symptoms as expected, but also regarding symptoms in general as measured with the Complaint Score instrument, also when differences between cases and referents in immigrant status, education, occupational status, income, and BMI were taken into account.

Table 2: Medical history

\begin{tabular}{|c|c|c|c|c|c|c|c|}
\hline & \multicolumn{2}{|l|}{ Cases } & \multicolumn{2}{|l|}{ Referents } & \multirow[b]{2}{*}{$\mathrm{p}<$} & \multirow[b]{2}{*}{ OR } & \multirow[b]{2}{*}{$95 \% \mathrm{Cl}$} \\
\hline & Mean or $\%$ & SD & Mean or $\%$ & SD & & & \\
\hline $\mathrm{N}$ & 138 & & 401 & & & & \\
\hline Tobacco use, $\%$ & & & & & n.s. & 1.08 & $0.89-|.3|$ \\
\hline Never smoked & 34.6 & & 45.0 & & & & \\
\hline Ex-smoker & 43.4 & & 31.0 & & & & \\
\hline \multicolumn{8}{|l|}{ Current smoker } \\
\hline I- $14 \mathrm{~g} /$ day & 14.7 & & 14.8 & & & & \\
\hline $15-24$ g/day & 4.4 & & 7.4 & & & & \\
\hline$\geq 25 \mathrm{~g} /$ day & 2.9 & & 1.8 & & & & \\
\hline Taking snuff & 4.4 & & 3.1 & & & & \\
\hline \multicolumn{8}{|l|}{ Low physical activity, \% } \\
\hline During leisure time & 86.6 & & 80.3 & & n.s. & 0.99 & $0.72-1.35$ \\
\hline During work & 50.0 & & 43.8 & & 0.001 & 0.24 & $0.18-0.33$ \\
\hline Height, $\mathrm{m}$ & 1.65 & 0.06 & 1.67 & 0.06 & 0.05 & 0.96 & $0.93-0.99$ \\
\hline \multicolumn{8}{|l|}{ Weight, kg } \\
\hline At age 20 & 55.9 & 7.3 & 57.7 & 7.8 & 0.05 & 0.97 & $0.94-0.99$ \\
\hline Five years ago & 69.7 & 12.5 & 57.7 & 7.8 & 0.05 & 1.02 & $1.00-1.03$ \\
\hline At present & 72.8 & 13.9 & 68.1 & 11.8 & 0.0005 & 1.03 & $1.01-1.05$ \\
\hline \multicolumn{8}{|l|}{ Body mass index, BMI } \\
\hline At age 20 & 20.6 & 2.5 & 20.8 & 2.5 & n.s. & 0.97 & $0.89-1.05$ \\
\hline Five years ago & 25.7 & 4.6 & 24.1 & 4.3 & 0.0005 & 1.08 & $1.04-1.13$ \\
\hline Maximum & 28.9 & 5.3 & 26.4 & 5.2 & 0.0001 & 1.08 & $1.05-1.12$ \\
\hline At present & 26.8 & 4.9 & 24.6 & 4.1 & 0.0001 & 1.11 & $1.07-1.16$ \\
\hline Body mass distribution, $\%$ & & & & & n.s. & & \\
\hline Waist & 24.0 & & 19.2 & & & 1.22 & $0.75-1.98$ \\
\hline Hips/thighs & 12.8 & & 19.4 & & & 0.64 & $0.36-1.15$ \\
\hline Both sites equal & 63.2 & & 61.4 & & & 1.00 & - \\
\hline Ever had underweight, \% & 35.6 & & 24.5 & & 0.05 & 1.70 & $1.12-2.59$ \\
\hline Excessive food intake, \% & 17.9 & & 8.0 & & 0.005 & 2.53 & $1.42-4.49$ \\
\hline
\end{tabular}

Lifestyle variables, weight and weight history, fibromyalgia duration and menstrual history. 
Table 3: Fibromyalgia symptoms

\begin{tabular}{|c|c|c|c|c|c|}
\hline & Cases & Referents & OR & $95 \% \mathrm{Cl}$ & $\mathbf{p}$ \\
\hline Constantly exhausted, \% & 89.0 & 34.7 & 10.67 & $5.78-19.69$ & $<0.0001$ \\
\hline Whole body fatigue, $\%$ & 91.9 & 36.9 & 16.31 & $7.84-33.93$ & $<0.0001$ \\
\hline Only muscular fatigue, $\%$ & 46.3 & 15.6 & 4.10 & $2.62-6.43$ & $<0.0001$ \\
\hline Tender points, $\%$ & 95.6 & 40.2 & 26.63 & II.37-62.38 & $<0.0001$ \\
\hline Sense of stiffness, $\%$ & 95.6 & 42.0 & 25.23 & $10.75-59.20$ & $<0.0001$ \\
\hline Sense of bloating, $\%$ & 72.1 & 22.1 & 6.30 & $3.81-10.43$ & $<0.0001$ \\
\hline Numbness, pins and needles, $\%$ & 77.2 & 26.4 & 5.48 & $3.27-9.19$ & $<0.0001$ \\
\hline Wakes up not thoroughly rested, \% & 86.0 & 45.2 & 6.95 & $4.10-11.78$ & $<0.0001$ \\
\hline Deteriorated short-term memory, \% & 73.5 & 28.9 & 4.66 & $2.86-7.59$ & $<0.0001$ \\
\hline Daily pain, dull aching, \% & 94.9 & 24.4 & 31.33 & $|3.82-7| .03$ & $<0.0001$ \\
\hline Pain at rest, $\%$ & 94.9 & 27.9 & 26.26 & $11.61-59.40$ & $<0.0001$ \\
\hline Awakened because of pain, $\%$ & 83.8 & 19.4 & 13.15 & $7.47-23.13$ & $<0.0001$ \\
\hline
\end{tabular}

Prevalence of fibromyalgia symptoms among cases and referents. OR = odds ratios adjusted for the influence of age, body mass index, education, occupational and immigrant status, $95 \% \mathrm{Cl}=95 \%$ confidence intervals.

The study was performed as a postal questionnaire study in patients fulfilling the 1990 ACR criteria and in a matched referent group sampled from the general population. The response rate among the cases was $92 \%$ and among the references a moderate $54 \%$. However, in the case-referent matched groups $90 \%$ had a responding case and $92 \%$ at least one responding referent. Since the analyses were conditional, i.e., the cases were systematically compared with their own referents, and all referents for a case are inter-changeable by definition, the response rate

Table 4: General symptoms

\begin{tabular}{|c|c|c|c|c|c|}
\hline & Cases & Referents & OR & $95 \% \mathrm{Cl}$ & $\mathbf{p}$ \\
\hline Cries easily, \% & 54.7 & 32.4 & 1.92 & $1.20-3.06$ & $<0.01$ \\
\hline Melancholy, \% & 78.1 & 47.9 & 3.04 & $1.85-5.00$ & $<0.0001$ \\
\hline General fatigue, $\%$ & 95.6 & 71.1 & 9.44 & $4.03-22.12$ & $<0.0001$ \\
\hline Insomnia, \% & 83.2 & 45.4 & 5.96 & $3.66-9.73$ & $<0.0001$ \\
\hline Exhaustion, \% & 67.2 & 43.1 & 2.79 & $|.85-4.2|$ & $<0.0001$ \\
\hline Irritability, \% & 75.9 & 45.1 & 4.25 & $2.7 \mid-6.69$ & $<0.0001$ \\
\hline Nervousness, \% & 43.1 & 14.2 & 3.16 & $1.93-5.18$ & $<0.0001$ \\
\hline Impaired concentration, \% & 80.3 & 37.4 & 7.11 & $4.43-11.40$ & $<0.0001$ \\
\hline Difficulty in relaxing, \% & 78.1 & 40.4 & 5.51 & $3.49-8.71$ & $<0.0001$ \\
\hline Restlessness, \% & 65.0 & 33.2 & 3.92 & $2.59-5.93$ & $<0.0001$ \\
\hline Headache, $\%$ & 82.5 & 53.4 & 4.40 & $2.69-7.18$ & $<0.0001$ \\
\hline Difficulty in passing urine, $\%$ & 11.7 & 3.7 & 1.88 & $0.85-4.16$ & 0.12 \\
\hline Bad appetite, $\%$ & 21.2 & 9.5 & 1.56 & $0.85-2.84$ & 0.15 \\
\hline Nausea, \% & 51.8 & 18.2 & 4.92 & $3.19-7.59$ & $<0.0001$ \\
\hline Diarrhoea, \% & 44.5 & 19.0 & 3.43 & $2.26-5.22$ & $<0.0001$ \\
\hline Constipation, $\%$ & 47.4 & 19.0 & 3.86 & $2.54-5.87$ & $<0.0001$ \\
\hline Abdominal pain, \% & 67.9 & 30.7 & 5.03 & $3.29-7.67$ & $<0.0001$ \\
\hline Pain in the joints, $\%$ & 93.4 & 35.7 & 17.60 & $8.33-37.19$ & $<0.0001$ \\
\hline Back ache, $\%$ & 93.4 & 44.4 & 16.70 & $8.22-33.93$ & $<0.0001$ \\
\hline Pain in the legs, $\%$ & 94.9 & 34.9 & 21.96 & $9.71-49.68$ & $<0.0001$ \\
\hline Feeling cold, \% & 61.0 & 32.4 & 2.36 & $1.46-3.82$ & 0.0005 \\
\hline Sweating, \% & 52.6 & 23.2 & 3.28 & $2.14-5.03$ & $<0.0001$ \\
\hline Loss of weight, \% & 6.6 & 5.5 & 0.87 & $0.36-2.07$ & 0.75 \\
\hline Overweight, \% & 47.4 & 27.7 & 1.51 & $0.92-2.49$ & 0.10 \\
\hline Breathlessness, \% & 45.3 & 16.5 & 2.44 & $1.47-4.05$ & 0.0005 \\
\hline Chest pain, \% & 41.6 & 13.7 & 3.85 & $2.43-6.10$ & $<0.0001$ \\
\hline Cough, \% & 30.7 & 24.2 & 1.19 & $0.76-1.86$ & 0.46 \\
\hline Dizziness, \% & 56.2 & 30.7 & 2.90 & $1.95-4.32$ & $<0.0001$ \\
\hline Impaired hearing, \% & 36.5 & 16.0 & 3.00 & $1.93-4.68$ & $<0.0001$ \\
\hline Eye problems, \% & 64.2 & 21.7 & 6.48 & $4.25-9.89$ & $<0.0001$ \\
\hline
\end{tabular}

Prevalence of general symptoms among cases and referents. OR = odds ratios adjusted for the influence of age, body mass index, education, occupational and immigrant status, $95 \% \mathrm{Cl}=95 \%$ confidence intervals. 
within the case-referent groups was satisfactory. It may be argued that the response among referents was selective. If so, the respondents were most probably healthier than non-respondents. On the other hand, the responding referent group had the same proportion of fibromyalgia patients as the corresponding age segment of the general population, i.e. approximately 12 subjects. We also know from another of our studies [17], that the Complaint Score level among the referents in the present study was similar to what is found in the corresponding segment of the general population. All things considered, the responding referents are most probably representative of the general population.

The questionnaires used were all validated except for the fibromyalgia symptom list, which was used as an instrument for the first time in this study. However, the list contains only well-known fibromyalgia symptoms. The recall time frames were generally short, 14 days to one year, with the exception of weight history. However, it has been shown that recall of height [18] and weight [19] at age 20 corresponds well with the corresponding medical record data. We therefore have no reason to believe that there would be selection or measurement bias to such an extent that the conclusions would be affected.

A number of descriptive studies on fibromyalgia patients have been presented. White et al. [11] investigated 100 fibromyalgia patients diagnosed according to the ACR criteria, 135 referents, age and sex matched to the fibromyalgia patients, and 76 patients with widespread pain of other origin. Mean age was 48 years, and $86 \%$ were women. Compared with referents, fibromyalgia patients tended to have lower income and educational levels, while there were no differences in marital status or reproductive history. As in our study, fibromyalgia patients reported more overall symptoms, more severe pain and fatigue, and worse overall health.

Henriksson and Liedberg [20] studied 176 female fibromyalgia patients, whose mean age and educational level were about the same as in our study. Fifty percent were still working, as compared with $26.6 \%$ among our cases. Wolfe et al. [21] studied work disability in 1,604 individuals with fibromyalgia, of whom $89 \%$ were women, mean age 48 years, and $42 \%$ were employed.

The present study appears to be the first controlled study based on random samples of cases and referents in which the higher prevalence is contrasted with the reporting in the corresponding age and sex segment of the general population. The distribution of reported general symptoms was the same in cases and referents, but the cases had a significantly higher prevalence of almost all symptoms. The higher general symptom prevalence among the cases may be due either to a higher true prevalence or to individuals with fibromyalgia having no more general symptoms than the general population but being more attentive to bodily symptoms. It is debatable whether fibromyalgia is merely an extension of the usual aches and pains of the general population, or whether the neuroendocrine stress and pain systems are triggered, making patients more susceptible to experiencing and reporting symptoms.

A true increase in symptom prevalence may be specific to fibromyalgia or unspecific and attributable to the presence of a chronic disease. In a recent study there was no significant difference between coronary heart disease patients and matched controls in Complaint Score reporting, indicating that chronic disease per se does not increase general symptom reporting [17]. In previous fibromyalgia studies, some controlled but none based on random samples, fibromyalgia patients had more general symptoms than rheumatic arthritis patients [22-25] and than patients with osteoarthritis and other pain syndromes $[11,23,24]$, making the possibility that the increased symptom prevalence was caused by chronic disease per se less likely. In any case, symptoms reported by subjects with fibromyalgia remain quite stable over the years, as has been shown in a longitudinal study [26].

Cases were immigrants to a significantly higher extent than referents. This may be explained in terms of the difficulties immigrants experience related to entering the labour market, because of language problems, etc. This circumstance might perhaps be involved in the aetiology of the condition.

There were also significantly more individuals among the cases who had ever suffered from underweight or excessive food intake. This was an unexpected finding. Individuals with fibromyalgia often have gastro-intestinal disturbances. There is a known co-morbidity between fibromyalgia and irritable bowel syndrome [27] and between fibromyalgia and rheumatoid arthritis [24,25]. It is not known whether there is a connection between the gastro-intestinal disturbances seen in patients with fibromyalgia and eating disorders, or whether eating disorders, per se might induce fibromyalgia, and the cause of the link fibromyalgia-rheumatoid arthritis as well appears to be unknown.

The diagnosis of fibromyalgia is usually based on the ACR criteria, which are quite specific and may be too narrow. The ACR criteria include specified tender points and widespread pain. However, individuals with fibromyalgia often have more general symptoms in addition. In a number of other conditions the symptom criteria are divided into A and B symptoms, for instance in chronic 
fatigue syndrome, lymphomas, and others. Using the same reasoning in fibromyalgia might then mean that the ACR criteria would constitute A symptoms and other reported symptoms, such as those in the present study, would constitute B symptoms.

\section{Conclusion}

In this case-referent study, the first controlled study of general symptom reporting in fibromyalgia patients based on random samples of cases and referents, we found significantly more frequent reporting of general symptoms among the patients than among referents. The cause may be either that fibromyalgia patients are more conscious of symptoms that others ignore or that fibromyalgia patients have a higher true prevalence of symptoms than referents, and thereby more symptoms than has generally been recognised.

\section{Competing interests}

SJ is and MAW was at the time of the data collection employees of AstraZeneca R\&D Mölndal. However, AstraZeneca had no drug on the market relating to the content of the manuscript. The study was partly funded by AstraZeneca R\&D Mölndal.

\section{Authors' contributions}

All authors participated in the data collection process and design of the data analysis. KB and KS performed the analyses and wrote the manuscript draft. All authors participated in the discussions of the results and in the revisions of the manuscript.

\section{Acknowledgements}

This study was supported by grants from AstraZeneca R\&D Mölndal and Uppsala University, Uppsala, Sweden.

\section{References}

I. Wolfe F, Ross K, Anderson J, Russel IJ, Hebert L: The prevalence and characteristics of fibromyalgia in the general population. Arthritis \& Rheumatism 1995, 38: 19-28.

2. Lindell L, Bergman S, Petersson IF, Jacobsson LTH, Herrström P: Prevalence of fibromyalgia and cronic widespread pain. Scand I Prim Health Care 2000, I 8: I 49-153.

3. White KP, Harth M: Classification, epidemiology, and natural history of fibromyalgia. Curr Pain Headache Rep 200I, 5:320-329.

4. Wolfe F, Ross K, Anderson J, Russel II: Aspects of fibromyalgia in the general population: sex, pain threshold, and fibromyalgia symptoms. J Rheumatol 1995, 22:15I-156.

5. Wolfe F, Smythe HA, Yunus MB, Bennett RM, Bombardier C, Goldenberg DI, et al: The American College of Rheumatology 1990 criteria for the classification of fibromyalgia. Report of the Multicenter Criteria Committee. Arthritis \& Rheumatism 1990, 33:160-170.

6. Pongratz DE, Sievers M: Fibromyalgia - symptom or diagnosis: A definition of the position. Scand J Rheumatol 2000, 29(Suppl I I3):3-7.

7. Chang L, Berman S, Mayer EA, Suyenobu B, Derbyshire S, Naliboff B, et al.: Brain responses to visceral and somatic stimuli in patients with irritable bowel syndrome with and without fibromyalgia. Am J Gastroenterol 2003, 98:|354-|36|.

8. Suhr JA: Neuropsychological impairment in fibromyalgia. Relation to depression, fatigue, and pain. J Psychosom Res 2003, 55:321-329.
9. Hughes G, Martinez C, Myon E, Taieb C, Wessely S: The impact of a diagnosis of fibromyalgia on health care resource use by primary care patients in the UK. Arthritis \& Rheumatism 2006, 54:177-183.

10. Zijlstra TR, Laar MAFJ van de, Bernelot Moens HJ, Taal E, Zakraoui L, Rasker J]: Spa treatment for primary fibromyalgia syndrome: a combination of thalassotherapy, exercise and patient education improves symptoms and quality of life. Rheumatology 2005, 44:539-546.

II. White KP, Speechley M, Harth M, Ostbye T: The London Fibromyalgia Epidemiology Study: Comparing the demographic and clinical characteristics in 100 random community cases of fibromyalgia versus controls. J Rheumatol I999, 26: I 577-I 585.

12. Liedberg GM, Burckhardt CS, Henriksson CM: Validity and reliability testing of the Quality of Life Scale, Swedish version in women with fibromyalgia - statistical analyses. Scand J Caring Sci 2005, 1 9:64-70.

13. Blackburn H, Prineas R: Cardiovascular survey methods. World Health Organization Geneva, Switzerland; 1989.

14. Tibblin G, Tibblin B, Peciva S, Kullman S, Svärdsudd K: "The Göteborg quality of life instrument" - An assessment of well-being and symptoms among Men born in 1913 and 1923. Methods and validity. Scand J Prim Health Care 1990:33-38.

15. Clauw DJ: Fibromyalgia: More than just a musculoskeletal disease. American Family Physician 1995, 52:843-85I.

16. SAS Institute Inc: [http://www.sas.com/technologies/analytics/statis tics/stat/factsheet.pdf]. (20 February 2004)

17. Gulliksson M, Burell G, Lundin L, Toss H, Svärdsudd K: Psychosocial factors during the first year after a coronary heart disease event in cases and referents. Secondary Prevention in Uppsala Primary Health Care Project (SUPRIM). BMC Cardiovascular disorders 2007, 7:36.

18. Eriksson M, Wallander MA, Krakau I, Wedel H, Svärdsudd K: The impact of birth weight on coronary heart disease morbidity and mortality in a cohort followed up for 85 years: a population-based study of men born in 1913. J Intern Med 2004, 256:472-48I.

19. Eriksson M: The impact of birth weight on cardiovascular risk factors, coronary heart disease and prostate cancer: population-based studies of men born in 1913 and followed up until old age. Uppsala University, Uppsala, Sweden; 2005.

20. Henriksson C, Liedberg G: Factors of importance for work disability in women with fibromyalgia. J Rheumatol 2000, 27:127I- 1276 .

21. Wolfe F, Anderson J, Harkness D, Bennett RM, Caro XJ, Goldenberg $\mathrm{DL}$, et al: Work and disability status of persons with fibromyalgia. J Rheumatol 1997, 24: | I7|-1 I78.

22. Yunus MB, Masi AT, Aldag JC: A controlled study of primary fibromyalgia syndome: clinical features and association with other functional syndromes. J Rheumatol 1989:62-7I.

23. Wolfe F, Hawley DJ: Evidence of disordered symptom appraisal in fibromyalgia: increased rates of reported comorbidity and comorbidity severity. Clin Exp Rheumatol 1999, 17:297-303.

24. Quimby LG, Block SR, Gratwick GM: Fibromyalgia: generalized pain intolerance and manifold symptom reporting. J Rheumatol 1988, I 5: 1 264-1270.

25. Wolfe F, Rasker J]: The Symptom Intensity Scale, fibromyalgia, and the meaning of fibromyalgia-like symptoms. J Rheumatol 2006, 33:229I-2299.

26. Mengshoel AM, Haugen M: Health status in fibromyalgia - A followup study. I Rheumatol 200I, 28:2085-2089.

27. Thompson D, Lettich L, Takeshita J: Fibromyalgia: An overview. Curr Psychiatry Rep 2003, 5:21 I-217.

\section{Pre-publication history}

The pre-publication history for this paper can be accessed here:

http://www.biomedcentral.com/1471-2458/9/402/pre pub 